\section{Life dissatisfaction among students: exploring the role of intrapersonal conflict, insufficient efforts and academic stress}

Insufficient efforts and academic stress

\author{
Anju, Amandeep, B.K. Punia and Vandana Punia \\ Naval Garg \\ Delhi Technological University, Delhi, India
}

Guru Jambheshwar University of Science and Technology, Hisar, India, and
Received 27 September 2020 Revised 6 December 2020 Accepted 21 December 2020

\begin{abstract}
Purpose - The study focuses on academic stress among the students due to insufficient efforts and intrapersonal conflicts amid the COVID-19 situation. The purpose of this study is to measure the mediating role of academic stress between life dissatisfaction and adequate steps and intrapersonal conflicts.

Design/methodology/approach - The researcher had surveyed 729 students from the two states, including Haryana and Punjab and 716 responses were used for analysis. These respondents were approached in April-May 2020 to explore the impact of COVID-19. The questionnaire was prepared with the help of Google form, including 29 questions. Confirmatory factor analysis and structural equation modeling (SEM) were used to validate the research model and for testing the hypothesis.

Findings - The findings indicate that intra-personal conflict and insufficient efforts have a significant positive relation with academic stress. Also, intrapersonal conflict and insufficient efforts have a significant positive relation with life dissatisfaction. It has been reported that academic stress mediates the relationship between life dissatisfaction and intra-personal conflict. The results also reveal that academic stress is positively and significantly associated with life dissatisfaction.
\end{abstract}

Originality/value - This is one of the few studies that explored the mediating role of academic stress between life dissatisfaction and insufficient efforts and intrapersonal conflicts.

Keywords Academic stress, Life dissatisfaction, Insufficient efforts, Intrapersonal conflicts

Paper type Research paper

\section{Introduction}

In today's world, students have to compete at every step-in academic resulting in a lot of stress. This growing academic pressure has resulted in "Academic stress." Researchers in recent literature have studied academic stress in university students (Gross, 2014, 2015a, 2015b; Freire et al., 2018; Phang et al., 2015). Chao (2012) shares that stress in university students can be a cumulative emotion, resulting due to academic uncertainty of the future, doubting self, difficulties in forming interpersonal- social relationships and many other

(C) Anju, Amandeep, B.K. Punia, Vandana Punia and Naval Garg. Published in Rajagiri Management Journal. Published by Emerald Publishing Limited. This article is published under the Creative Commons Attribution (CC BY 4.0) licence. Anyone may reproduce, distribute, translate and create derivative works of this article (for both commercial and non-commercial purposes), subject to full attribution to the original publication and authors. The full terms of this licence maybe seen at http:// creativecommons.org/licences/by/4.0/legalcode 
RAMJ

15,2

114

reasons. Gupta and Khan (1987) defined it as a "mental distress concerning some anticipated frustration associated with academic failure or even awareness of the possibility of such failure."

Though stress is "normative" in the developmental period, there are times when this stress has been found to persist later in life also. Situations, where extreme stress is experienced by the student, can be fatal. Bhujade (2017) shared that at any given time, 10 $20 \%$ of students are suffering from some form of mental health problem in Indian colleges. These mental health problems may be an outcome of increased stress and may appear in the form of anxiety and depression (Kumaraswamy, 2013). Suffering from mental health issues while pursuing academics may be dysfunctional for the student. Also, these stress levels influence one's satisfaction with university and life in general (Jenkins et al., 2013).

Academic stress is a generalized phenomenon, it can be experienced at school and college (university) level. Students may experience it independent of their academic performance or capability. Academically weaker students may be worried about their performance in class, while others are worried about maintaining or bringing up their grades. Conditions in the family such as divorce, intrapersonal conflicts and marital depression can affect the functioning of the student (Forehand et al., 1991). An unsupportive environment at home/school causes a feeling of burden among students, which leads to suicidal ideation (Arun and Chavan, 2009). Also, students' personal expectations to excel and that of their parents and teachers contribute to the building up of academic stress (Ang and Huan, 2006; Deb et al., 2014).

It is interesting to note that there are differences in the experience of stress in female and male students, especially in the Indian context. Verma and Verma (2020) have shared that women experience stress due to lack of support and men are burdened due to the expectations of the parents. They feel that as their parents are supporting them financially and emotionally (friends, family, relatives, etc.), they in return may have some expectations such as good academic scores, better career and achievements. This belief in a student's mind builds pressure that as he or she is getting all the facilities and support from the surrounding, he/she has to perform better to fulfill these expectations. This increased pressure and deteriorating mental health of students on campus is a concern as that affects the psychological health of students and that of future adults. Recent work reveals that academic stress should be kept under control for students to have a rewarding experience at the university (Freire et al., 2018).

The current paper focuses on two variables that can be the reason for academic stress in student life. These two variables are personally related to an individual and vary according to his or her personality type. These cognitive factors influence the level of stress experienced, leading to the satisfaction experienced by the student toward life. It is important to note that there are prior personal characteristics that influence the experience of stress in students (de la Fuente, 2015; Craig et al., 2020).

The first variable in the study is insufficient effort. Here the term efforts mean the strength of a student that he or she puts into performing better in their academic life. Insufficient efforts can become the reason for poor performance. It directly affects the stress level in a student's life. Not only a weak student but a brilliant student also gets deviated from his path and is not able to focus on his goal, thus affecting the level of effort they put into their task. With increased competition in academics, insufficient efforts can make your performance lag. All these things are the main reasons for academic stress in a student's life.

Another variable we have used here is intrapersonal conflicts. Bazerman et al. (1998) identify intrapersonal conflict as a discrepancy between what they want to do and what they should do. The positive and negative thoughts and feelings which one would hold toward an attitude or object create intrapersonal conflicts. The contradictions which the students 
experience internally could be due to motivation to do something or conflicts of self-esteem or many other factors (Gerasimova and Gerasymova, 2019). These differences which internal selfexperiences with the external environment contribute to conflicts are experienced by them. For intrapersonal conflicts to arise, there is a need for a personal and social condition to be present and academics can be seen as one of the conditions. The cognitive dissonances experienced by the individual can contribute to the development of intrapersonal conflicts. In the current study, we are discussing conflict within oneself. When students have some uncertain feelings about themselves and their capabilities, they find themselves in a dilemma. They start to doubt their capabilities, which becomes a hurdle in their performance. As the dilemma increases in their life, it directly impacts their academic performance and increases the stress experienced. As stress directly impacts an individual's life, in the same way, academic stress negatively affects the student's life. In this current study, the researchers also focus on the negative impact of academic stress on students' satisfaction level in life. The current paper is focusing on the relationship between stressors of academic stress and life's dissatisfaction.

\section{Literature review}

\section{Academic stress among students}

Academic stress has been defined as a negative and undesirable response of students toward academic environmental stressors (Lee and Larson, 2000). It also includes students' appraisal, analysis and reactions to studies, institutions and career-related stressors. Owing to the gravity of issues and challenges posed by academic stress, it has been termed as a "career stopper" (Kadapatti and Vijayalaxmi, 2012). Subramani and Kadhiravan (2017) proposed a linkage between academic stress and mental health. The authors clarified that students often get cramped and caged in academic structure and they hardly find any route to deal with the academic stressors. Nandamuri and Gowthami (2011) argued that academic stress is one of the main reasons for the exponential rise in mental health issues among Indian youth. Sharma et al. (2016) opined that academic stress might lead to students' mental and physical challenges. Deb et al. (2014) and Beiter et al. (2015) reported that academic stress might be observed in the form of depression, anxiety, intolerance, anger, irritability, loss of concentration and focus and withdrawal symptoms in students.

In some cases, students resort to extreme deviant behaviors such as suicide, run-away from home, drug addiction break institutional rules and procedures (Garg and Saxena, 2020). Huang et al. (2020) study how uncivil behavior and academic stress influence the psychological health of the student. Busari (2012) suggested that a stressed mind and body make it difficult for a student to concentrate. It fills the student with negative emotions and subsequently, an unknown fear of failure surrounds the student. Several researchers, including Saxena et al. (2020), reported that excessive stressful adolescent students are more prone to indulge in alcoholism and drug abuse. Few other undesirable repercussions of stressed academic life are physical and mental inactivity, dullness, eating and sleeping habit disorder and unprotected and failed sexual life.

Studies have shown that a mild level of stress is conducive for the student and that lowering the level of stress does not ensure better performance. A student may consider a situation with no stress as non-challenging and the performance may reduce significantly (Uchil, 2017). Thus, practitioners and academicians opined that a certain threshold level of stress might encourage students to perform better. Caution is that prolonged stress or inadequately managed stress negatively influences students' prospects and academic institutions. Mishra and Mckean (2000) argued that, apart from stressors, lack of synergy and synchronization of stressors and students' approach to cope with these stressors create tension, anxiety and depression among students.
Insufficient efforts and academic stress

115 
RAMJ

15,2

116

Researchers and academicians agree that prevailing challenging conditions emerging out of pandemic COVID-19 have aggravated students' academic stress (Bhat et al., 2020). Students' anxiety level has shot-up due to uncertainty over classes and examinations, physical distancing, longer screen time, poor connectivity in rural areas, lack of laptops or desktops, etc. Pandemic has resulted in reduced motivation and morale of students toward studies, increased pressures to learn independently, desertion of daily routines, reduced approachability of faculty members and potentially higher dropout rates (Grubic et al., 2020). Sheroun et al. (2020) reported that academic stress took an inverted "U" shaped graph in the lockdown period. Academic stress was lower in the first 13 days of lockdown; then, it raised sharply for the next 15 days. There on, it decreased after one month, but this level was quite higher than the first 13 days (Sheroun et al., 2020). These studies highlight the importance of understanding academic stress during the COVID-19 situation.

\section{Interpersonal conflict, insufficient efforts and academic stress}

Previous researchers have discussed several reasons for academic stress among students. These reasons include homesickness, fear of failure, the pressure of studies, competition, financial hardship, etc. Zeidner (1992) elaborated that there are physical conditions, economic factors, a psychological weakness, etc., which contribute to academic stress. Detailing further on, Kohn and Frazer (1986) observed 35 academic stressors for students. These stressors were the uncertainty of final grade, examination, boring classes, parents and self-expectations, etc.

Amid these multiplicities of academic stressors, interpersonal conflict and insufficient efforts are being explored for their probable role in students' academic stress. The present study explores the effect of these two stressors on students for the following reasons. Intrapersonal conflicts contribute to stress, independent of other stresses present in the environment (Lauterbach, 1991). Mikolaj and Boggs (1991) studied how intrapersonal conflicts contribute to stress in adult students. Researchers studying academic stress argued that roles that require a higher level of interpersonal- interactions are more stressful. "Interpersonal problems. . ranks as a primary source of unhappiness in people's lives. A construct that measures the quality of interpersonal relationships at work is interpersonal conflict" (Jaramillo et al., 2011). Then, a student must develop interpersonal skills to interact with teachers, colleagues and other stakeholders of a college. It is noteworthy to understand that individual personality differences may give rise to interpersonal conflict among students. Interpersonal conflict is defined as negative interactions with co-workers, supervisors or clients, which leads to heated arguments, unfriendly or violent behavior. Among students, interpersonal conflict may manifest as unhealthy competition, backbitting, criticism, ostracism, quarrel and grouping. It is interesting to note that most interpersonal conflicts lead to petty arguments and gossip, not physical and violent attacks (Schat, Frone and Kelloway, 2006). Keenan and Newton (1985) suggested that interpersonal conflicts elicit anger, frustration and stress in people who encounter them. It has also been argued that interpersonal conflicts are more detrimental to mental health than noninterpersonal conflicts (Taniguchi and Kato, 2018). Students have reported that the institution community's social interactions are among the most challenging parts of their school careers (Pyhältö et al., 2010). The supportive relationships with school friends and teachers play a pivotal role in students' well-being and successful adaptation to educational context (Longobardi et al., 2016). Several other researchers such as De Dreu et al. (2004), Jamadin et al. (2015), Karatepe and Baddar (2006), Applebaum et al. (2010), Wang et al. (2018), Fuller et al. (2003) and Miller (1989) supported the view that interpersonal conflict 
leads to stress. Stress negatively influences the academic achievement of university students.

Insufficient efforts represent the students' lack of willpower and low-level efforts to resolve the problems, leading to stress (Fuller et al., 2003; Miller, 1989). A student may find it difficult to devote equal efforts to studies, relationship management and physical and mental health well-being. Misdirected efforts, imbalanced efforts and insufficient efforts hinder goal achievement, eliciting anger and stress among students (Jamadin et al., 2015). The following hypotheses were proposed to explore the proposed relationships between efforts and academic stress academic stress, interpersonal conflict and insufficient efforts.

\section{Life dissatisfaction, interpersonal conflict, insufficient efforts and academic stress}

Life satisfaction is one of the most vibrant constructive and positive adjustment indicators influenced by students' stress during their academic life (Çivitci, 2015). Life satisfaction has been considered one of the three components of subjective well-being (Çivitci, 2015). The other two tenants of subjective well-being, positive and negative, consider pleasant and unpleasant emotions only. However, life satisfaction talks about the cognitive evaluation of individuals' lives (Diener and Suh, 1997). Thus, life satisfaction is a much more enduring, stable, reliable and important factor of subjective well-being because it allows long-term evaluations (Eid and Diener, 2004). Apart from being an indicator of subjective well-being, life satisfaction also indicates the objective quality of life such as health, financial status, freedom and entertainment (Diener and Suh, 1997).

Life satisfaction has been associated with college success and has been found to contribute to limiting mental health symptoms and low stress (Jenkins et al., 2013). However, increased college stress has been associated with lower life satisfaction (Brougham et al., 2009). Ng et al. (2020), in their research, established the relation of intrapersonal factors and life satisfaction among youth. They share that higher intrapersonal conflicts lead to lower life satisfaction, especially for young adults.

Burger and Samuel (2017), in their longitudinal study, demonstrated that internally stronger students are able to better deal with stress during difficult transitions in life. These cognitive factors, if they have strength, mitigate the negative effect of stress, thereby leading to greater life satisfaction.

Ben-Zur (2009), in his study, shared that well-being is associated with social support and coping. Parental support and teacher support and counseling play an important role (Virtanen et al., 2019) in providing that strength to the students in dealing with stress. In this study, the negative connotation of life satisfaction, i.e. life dissatisfaction, was explored. The authors proposed that interpersonal conflict and insufficient efforts lead to life dissatisfaction among students. These relationships are also proposed to be mediated by academic stress. Accordingly, the following model (Figure 1) and hypotheses were proposed. Figure 2 represent results of the hypothesized model..

H1. There is a significant relationship between insufficient efforts and academic stress.

H2. There is a significant relationship between insufficient efforts and life dissatisfaction.

H3. There is a significant relationship between intrapersonal conflicts and academic stress.

H4. There is a significant relationship between intrapersonal conflicts and life dissatisfaction. 
RAMJ

15,2

118

Figure 1.

Hypothesized model

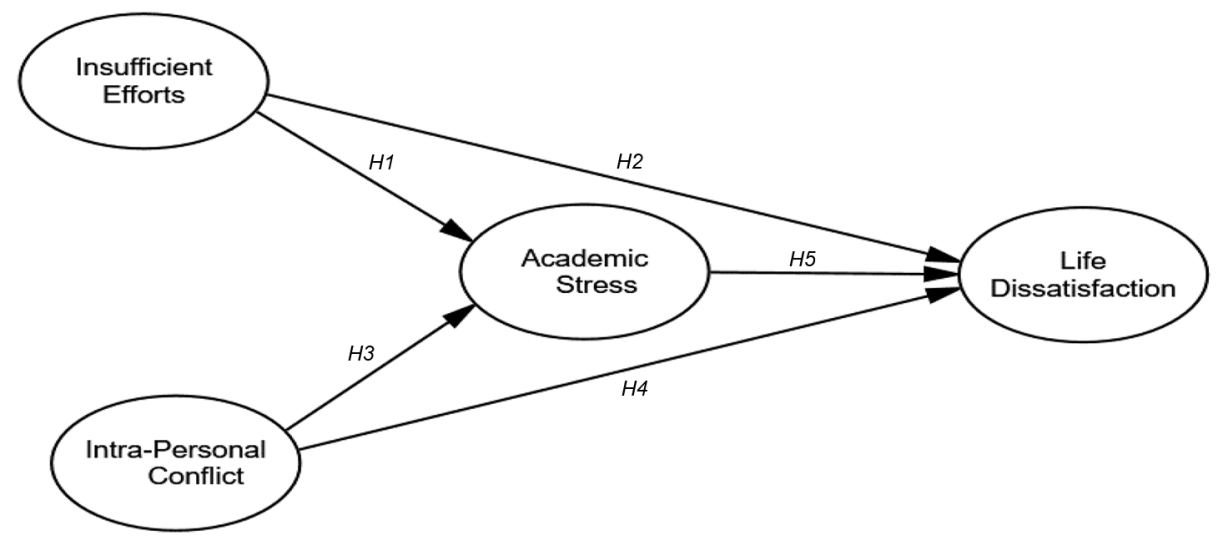

Source: Author's Own

Figure 2.

Model results

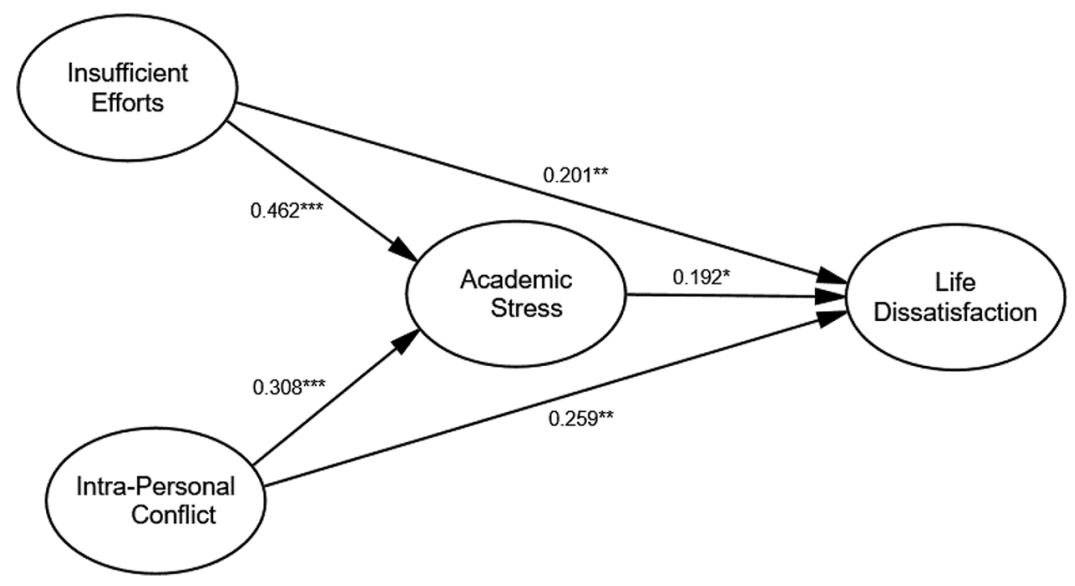

Source: Primary data

H5. There is a significant relationship between academic stress and life dissatisfaction.

H6. The positive relationship between intrapersonal conflicts and life dissatisfaction is mediated by academic stress.

H7. The positive relationship between insufficient efforts and life dissatisfaction is mediated by academic stress.

\section{Methodology and hypothesis development}

Method

Data collection and the sample. The survey was conducted on college students from two states- Haryana and Rajasthan. The questionnaire was prepared on Google forms, which included 35 questions. In all a sample of 729 students was collected, of which 14 responses 
were excluded where 10 were found to be not engaged and 3 had duplicity. Hence, a sample of 716 was used for analysis. In the final sample, $472(65.9 \%)$ were female and $244(34.1 \%)$ were male. There were, $509(71.1 \%)$ respondents pursuing graduation, $174(24.3 \%)$ postgraduation and $33(4.6 \%)$ were enrolled in Ph.D. Out of 716 respondents, $82.1 \%$ were living in their residence, $8.2 \%$ stayed in college/university hostel, $5.3 \%$ in relative house, $3.6 \%$ were living in a rented room and $0.7 \%$ in PG. Of the 716 respondents, $54.7 \%$ belonged to rural areas and $45.3 \%$ were from urban areas.

\section{Measures}

To measure academic stress 7 -items scale was used from a 21-item inventory of academic stress (Lakaev, 2009) and 2 items were dropped due to low factor loading. To measure the insufficient efforts and intrapersonal conflicts, an 11-item scale was used from the Level of attribution and change (LAC) scale (Norcross et al., 1985). All the items of Satisfaction with life scale (SWLS) were modified for measuring life dissatisfaction (Diener et al., 1985) and 3 items were used for this scale and 2 items were dropped due to low factor loadings. We measured all of the items on a five-point Likert scale ranging from "strongly disagree" (1) to "strongly agree" (5).

\section{Normality, reliability, validity and common method variance estimates}

We observed a fairly normal distribution for our indicators of latent factors in terms of skewness. However, we observed mild kurtosis for the indicators of our dependent variable life satisfaction (LS), mediator academic stress (ACS) and independent variables interpersonal conflicts and Insufficient efforts (IPC and IE). The kurtosis values ranged from benign to 1.898. While this does violate strict rules of normality, it is within more relaxed rules suggested by Sposito et al. (1983), who recommended 3.3 as the upper threshold for normality. We ran cook's distance analysis to determine if any (multivariate) influential outlier existed. In no case did we observe a cook's distance greater than 1 . Most cases were far less than 0.025 . Cronbach's $\alpha$ values of all the variables were more than the 0.70 threshold value considered acceptable by Cortina (1993) revealing satisfactory reliability of all the constructs. The Composite Reliability (CR) of each scale exceeded the value of 0.70 thresholds for acceptable reliability (Bagozzi and Yi, 1988; Nunnally, 1994) and that the AVE value exceeded the recommended threshold of 0.5 (Bagozzi and Yi, 1988; Fornell and Larcker, 1981). Finally, as shown in Table 1, the AVE's square root exceeded all the correlations (Fornell and Larcker, 1981), demonstrating sufficient discriminant validity between the constructs. Also, Heterotrait-Monotrait ratio (HTMT) criteria were adopted to prove discriminant validity between constructs. All the ratios were less than the $\mathrm{HTMT}_{85}$ criteria (Kline, 2011), demonstrating sufficient discriminant validity between the constructs

\begin{tabular}{lccccccc}
\hline Variables & Mean & SD & $\alpha$ & 1 & 2 & 3 & 4 \\
\hline 1. ACS & 2.57 & 0.955 & 0.792 & 0.739 & & & \\
2. IE & 2.44 & 1.019 & 0.863 & $0.590^{* * * *}$ & 0.804 & & \\
3. IPC & 2.23 & 0.954 & 0.872 & $0.571^{* * * *}$ & $0.704^{* * * *}$ & 0.781 & 0.803 \\
4. LDS & 2.09 & 0.724 & 0.727 & $0.385^{* * * *}$ & $0.439^{* * * *}$ & $0.451^{* * *}$ & 0.844 \\
5. CR & & & & 0.856 & 0.901 & 0.903 & 0.803
\end{tabular}

Notes: SD, standard deviation; ACS, academic stress; IPC, inter-personal conflict; IE, insufficient efforts; LDS, life dissatisfaction; CR, composite reliability; $\alpha$, Cronbach's alpha; diagonal italic values represent $\checkmark$ AVE; **** $p<0.001$
Insufficient efforts and academic stress

119

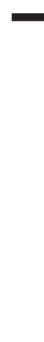




$\begin{array}{llcc}\text { RAMJ } & \text { Direct effects } & \text { Standardized } & t \text {-value } \\ \text { 15,2 } & \text { coefficient } & 3.853^{* * *} \\ & \text { Intra-personal conflict } \rightarrow \text { academic stress } & 0.308 & 5.464^{* * * *} \\ & \text { Insufficient efforts } \rightarrow \text { academic stress } & 0.462 & 2.597^{* *} \\ & \text { Intra-personal conflict } \rightarrow \text { life dissatisfaction } & 0.259 & 2.784^{* *} \\ & \text { Insufficient efforts } \rightarrow \text { life dissatisfaction } & 0.201 & 2.048^{*} \\ \mathbf{1 2 0} & \text { Academic stress } \rightarrow \text { life dissatisfaction } & 0.192 & \text { Standardized } \\ & \text { Indirect effects } & p \text {-value } & \text { coefficient } \\ & \text { Intra-personal conflict } \rightarrow \text { academic stress } \rightarrow \text { life } & 0.014 & 0.051(0.011-0.111) \\ & \text { dissatisfaction } & & 0.017 \\ & \text { Insufficient efforts } \rightarrow \text { academic stress } \rightarrow \text { life dissatisfaction } & & 0.072(0.013-0.154)\end{array}$

Table 2.

Mediation results
Note: $* * * p<0.001, * * p<0.01, * p<0.05$. Numbers in brackets represent the $95 \%$ bias-corrected and accelerated confidence intervals derived from bootstrapping with 2,000 samples

Source: Primary data

as shown in Table 3. CFA was used to examine the reliability and validity of study measures. The results revealed that the measurement model fitted the data well for study: $\chi^{2}(141)=376.754, \chi^{2} / \mathrm{df}=2.67, \mathrm{GFI}=0.947, \mathrm{CFI}=0.962, \mathrm{TLI}=0.933, \mathrm{RMSEA}=0.048$ (Hair et al., 1998; Hu and Bentler, 1999). Previous research indicates a good fit of the model and the data if the RMSEA value is less than 0.05 (NE and Cudeck, 1993). Further, the value of standardized RMR is 0.0363 . All the factor loads were significant and had a value of over 0.5 (Stevens, 2012).

As we collected the data of dependent and independent variables from the same respondent through self-reporting, there could be common method variance (CMV). Harman's single factor test explained total variance explained of $41.036 \%$ by a single factor, so there is no common method bias in our data set. We also conducted a confirmatory factor analysis to compare the four-factor model with a single-factor model in which all items were loaded on a single factor (Podsakoff et al., 2003). According to the fit indices ( $\chi^{2}=1,398.042$, $\mathrm{df}=152, p=0.000 ; \mathrm{GFI}=0.801 ; \mathrm{TLI}=0.772, \mathrm{CFI}=0.797 ; \mathrm{RMSEA}=0.107$ ), the single-factor model provided an unacceptable fit to the data, implying that CMV was not a serious issue.

\section{Results}

Table 1 shows the correlations between all the variables and correlations were all in the expected direction. The findings demonstrate that academic stress is positively correlated with insufficient efforts $(r=0.716, p<0.001)$, intra-personal conflicts $(r=0.691, p<0.001)$ and life dissatisfaction $(r=0.513, p<0.001)$. Life dissatisfaction is positively correlated with intra-personal conflict $(r=0.551, p<0.001)$ and insufficient efforts $(r=0.549, p<0.001)$.

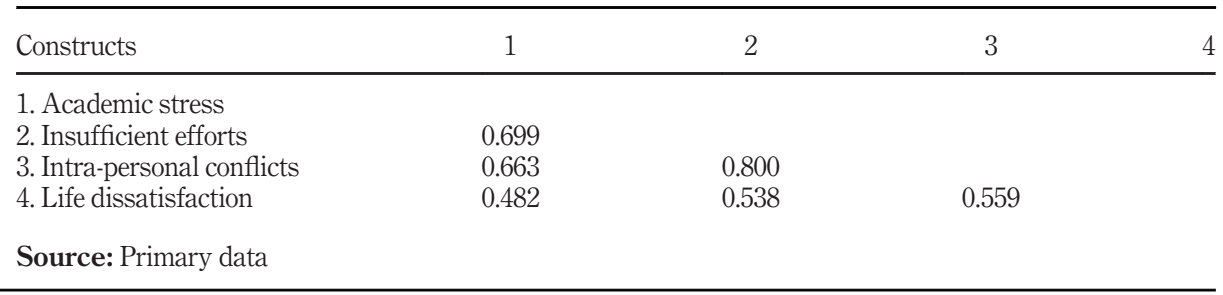

Table 3.

Assessment of discriminant validity using the HTMT

Source: Primary data 
To analyze the validity of our proposed hypotheses, we used SEM procedures with maximum likelihood estimation. The structural model analysis indicated a good fit, as judged from the goodness-of-fit indices $\chi 2=375.372 ; \chi 2 / \mathrm{df}=2.662 ; p<0.001 ; \mathrm{CFI}=0.962$; $\mathrm{GFI}=0.949 ; \mathrm{AGFI}=0.931 ; \mathrm{RMSEA}=0.048 ; \mathrm{RMR}=0.07 ; \mathrm{SRMR}=0.0369$.

The findings, as depicted in Table 2 , indicate that intra-personal conflict and insufficient efforts are positively related to academic stress $\left(\beta_{I P C \rightarrow A C S}=0.308, p<0.001\right.$ and $\left(\beta_{I E \rightarrow A C S}=0.462, p<0.001\right.$, respectively). Therefore, $H 1$ and $H 3$ are supported. In addition, intrapersonal conflict and insufficient efforts also have significant positive relation with life dissatisfaction $\left(\beta_{I P C \rightarrow L D S}=0.259, p<0.01, \beta_{I E \rightarrow L D S}=0.201, p<0.05\right.$, respectively). Hence, $H 2$ and $H 4$ are supported. In $H 3$, we hypothesized that academic stress positively affects life dissatisfaction. The results reveal that academic stress is positively and significantly associated with life dissatisfaction $\left(\beta_{\mathrm{ACS} \rightarrow \mathrm{LDS}}=0.192\right.$, $p<0.01)$. Hence, H5 is supported. Moreover, the bootstrapping analysis suggests that academic stress mediates the relationships between intra-personal conflicts $\left(\beta_{\mathrm{IPC} \rightarrow \mathrm{ACS} \rightarrow \mathrm{LDS}}=0.051, p<0.05\right)$, insufficient efforts $\left(\beta_{\mathrm{IE} \rightarrow \mathrm{ACS} \rightarrow \mathrm{LDS}}=0.072, p<0.05\right)$ and life dissatisfaction. Thus, $H 6$ and $H 7$ are supported.

\section{Discussion}

The current study is conducted to measure the effects of insufficient efforts and intrapersonal conflicts on students' academic stress and life dissatisfaction. The results of the study established academic stress as a mediating variable between the two personal factors and life dissatisfaction. In the period of this pandemic, the academic life of every student is becoming more stressful as compared to the pre-pandemic period. The current paper discusses the two variables that cause academic stress and life dissatisfaction among students. $H 1$ assessed the relationship between insufficient efforts and academic stress; the result of the study supported the hypothesis with a standardized coefficient of 0.308 at a $0.1 \%$ level of significance - the student exhibiting insufficient efforts to experience academic stress. Due to the present pandemic condition, students are experiencing new situations every day. These situations deviate from the normal and many of these are beyond the control of the student. Thus, making it difficult for the student to give their best effort and thereby experiencing greater academic stress (Jamadin et al., 2015). The students may lack the capability or assume that they lack the capability to do the desired task. To further see the effect of insufficient efforts, $H 3$ proposed a relation between insufficient effort and life dissatisfaction. The result was supported with a standardized coefficient of 0.462 at a $0.1 \%$ level of significance. The students who experience insufficient efforts can also experience greater dissatisfaction regarding life. These new challenging times may leave the students demotivated, leading to a lower level of effort toward their academic goals (Miller, 1989). Their doubts about competence lowered willpower and not working hard enough can be accentuated by the ongoing pandemic. It is important to note that students in the past have not been exposed to such difficult challenges. They do not have the mental strength or experience to deal with negativity, thus leading to greater life dissatisfaction.

$H 2$ assessed the relationship between intrapersonal conflicts and academic stress. The result of the study confirmed the positive relationship between the two variables with a standardized coefficient of 0.201 at a $0.1 \%$ level of significance. The students experience more stress when their intrapersonal conflicts are on the rise. The internal discordance of the students in these unprecedented times would be on the rise. There would have difficulty in experiencing their true feeling, with uncertainty about self and lack of knowledge on how the self should behave in the present situations. The students do not know how to present their inner self in this condition, which has led them to a state of cognitive dissonance,
Insufficient efforts and academic stress 
RAMJ

15,2

thereby increasing their level of stress (Gerasimova and Gerasymova, 2019). Further on, $H 4$ assessed the influence of intrapersonal conflicts on life dissatisfaction and the result of the study confirmed the relationship with a standardized coefficient of 0.259 at a $0.1 \%$ level of significance. The greater the internal conflicts are for the students, the more dissatisfied they are with their life. Contemporary work by supports the findings for youth where intrapersonal conflicts are inhibitive of students to experience satisfaction toward life. These internal conflicts can lead students to experience mental health symptoms (Jenkins et al., 2013).

The findings of the study also support $H 5$, which had proposed a relation between academic stress and life satisfaction with a standardized coefficient value of 0.192 at a $5 \%$ level of significance. The increased stress which the student experiences will have an impact on their satisfaction toward life. Studies (Bhat, 2020 and Sheroun et al., 2020) have established that this pandemic has contributed to increasing stress level of the students with a change in an academic set up such as uncertainty over classes and examinations, physical distancing, longer screen time, poor connectivity in rural areas and lack of laptops or desktops. Our findings are supporting the studies which have established the association between academic stress and life dissatisfaction (Brougham et al., 2009). The study in their $H 6$ and $H 7$ proposed to see the indirect effect of insufficient effect and intrapersonal conflict on life dissatisfaction mediated through academic stress. The role of academic stress was established as a mediating variable.

The findings of the study highlight the critical role of student's personal experiences and how they can influence academic and personal well-being. These internal difficulties can lead to a negative influence on the academic performance of the student and could deter his progress in his career (Kadapatti and Vijayalaxmi, 2012). As a result, have shared the mounting intrapersonal conflicts and insufficient efforts lead to academic stress and life dissatisfaction, which can result in mental health problems or symptoms (Sharma et al., 2016; Deb et al., 2014). Subramani and Kadhiravan (2017) had established how the student finds it difficult to deal with the academic stressors and they are unable to find ways to deal with them. Academic failure and dissatisfaction with life can also lead to other forms of deviant behaviors (Saxena et al.,2020).

For the well-being of the youth, reducing these individual effects of the personal factors would be critical to reducing the mounting life satisfaction. The ongoing pandemic surely has contributed to the challenges the students are facing. Students might not be able to share them with anyone, as they are restricted in their home environment. Studies (Kong et al., 2015) have established that developing a support system for the student can be influential in lower life dissatisfaction experienced by the students. The support system which is provided by the school, teacher, classmates and family members is critical for satisfaction at school and that can influence life satisfaction (Danielsen et al., 2009). The support from friends and family acts as a protective shield for the students. Due to limited support in these times, establishing a system to protect the student would be useful for dealing with some of the internal challenges which the students are experiencing.

A psychological support system can help deal with the personal challenges of the student. These challenges at an internal level such as self-efficacy, self-esteem, capability issues, complexes should be dealt with by professional experts. Psychologists and counselors introduced into the system can help the student to deal with these issues. Studies have shared that students have an increased perception of stress when they have dysfunctional coping strategies (Chao, 2012). Establishing these psychological support systems can rectify these dysfunctional coping with correct life 
skills for personal development. Also, the university should provide information about career-related issues and future related prospects to help with the uncertainty experienced in the present times. There is a positive relationship between social support systems and reducing stress and increasing life satisfaction (Coffman and Gilligan, 2002). Developing a safe, supportive environment would reduce academic stress and also moderate the capability of students to recover from these difficulties (Wilks, 2008).

\section{Practical implication}

Our study has important implications for the academic stress that students experience at the university level. It is crucial to control factors that contribute to and build academic dis-stress for students. The personal and internal challenges which the student experiences should be addressed in a non-threatening and supportive environment. First, the university should look into developing a system that addresses these issues with professional experts (psychologists and counselors) through facilities of counseling and support systems (career counseling and guidance, etc.) at the university level. Emotion-focused coping strategies through these support systems would be useful in dealing with mental health challenges (Brougham et al., 2009). Second, establishing a mentor-mentee program has been found to be useful in the past (Bhujade, 2017); thus, focusing on developing such a buddy relationship can be useful in university settings. Developing such close bonds can be useful to closely monitor the health of the students and look into the personal challenges early on which the students might experience. Thirdly, establishing career and counseling and guidance centers at the university level for the student to find one point source for authentic information for their career-related concerns. In the current times of COVID-19, with increased stress, it is a dire need to address the internal issues of the students to strengthen their mental well-being and increase life satisfaction and success at university.

\section{Limitation and future research}

The present study has limitations, which should be kept in consideration. The study was conducted in the environment of coronavirus pandemic. The external environment could influence the results of the study, and hence should be generalized with caution. Second, the data was collected through an online survey, the researcher was not able to contact the respondent directly. The third limitation of the study is that it excludes school students. Further research, including school students, may show some different results. Fourth the study has been conducted in the northern and central regions of the country, which does not represent the whole country due to regional and cultural differences. This can also be limited to the generalization of the study. The study does not look at the differences in academic stress for students in different fields and specialization, which also gives scope for further research.

Based on the finding of the current study, some points are recommended for further research. First, the presence of social support and family support/environment can be an important factor to contribute as a moderator to the variables explored in the present study. Second, exploring academic stress in school students can be useful, especially in the board class students (10th and 12th) as their personal factors can be critical in contributing to stress and life dissatisfaction. Another dimension to look at is when we deconstruct academic stress with respect to the stress of the teaching and learning process and personal factors, which contribute to academic stress especially in the Indian context.
Insufficient efforts and academic stress 
RAMJ

15,2

\section{Conclusion}

The study confirmed the proposed hypothesis that there is an effect of insufficient efforts and intrapersonal conflict on academic stress. The increased academic stress increases life dissatisfaction among the students at the university level. These internal influencers of intrapersonal conflicts and insufficient conflicts influence the life dissatisfaction of the students. The study highlights the need to focus on the psychological needs of the student as increased discordance can develop into academic stress and influence the general meaning of life in a negative way. These challenging times of COVID may bring greater internal discrepancies; universities and colleges should help in creating a supportive environment with services and systems that can help students tide over these difficult times.

\section{References}

Ang, R.P. and Huan, V.S. (2006), "Academic expectations stress inventory: development, factor analysis, reliability, and validity”, Educational and Psychological Measurement, Vol. 66 No. 3, pp. 522-539.

Applebaum, D., Fowler, S., Fiedler, N., Osinubi, O. and Robson, M. (2010), "The impact of environmental factors on nursing stress, job satisfaction, and turnover intention", JONA: The Journal of Nursing Administration, Vol. 40 Nos 7/8, pp. 323-328, doi: 10.1097/ NNA.0b013e3181e9393b.

Arun, P. and Chavan, B. (2009), "Stress and suicidal ideas in adolescent students in Chandigarh", Indian Journal of Medical Sciences, Vol. 63 No. 7, p. 281, doi: 10.4103/0019-5359.55112.

Bagozzi, R.P. and Yi, Y. (1988), "On the evaluation of structural equation models", Journal of the Academy of Marketing Science, Vol. 16 No. 1, pp. 74-94.

Bazerman, M.H., Tenbrunsel, A.E. and Wade-Benzoni, K. (1998), "Negotiating with yourself and losing: making decisions with competing internal preferences", Academy of Management Review, Vol. 23 No. 2, pp. 225-241.

Beiter, R., Nash, R., McCrady, M., Rhoades, D., Linscomb, M., Clarahan, M. and Sammut, S. (2015), "The prevalence and correlates of depression, anxiety, and stress in a sample of college students", Journal of Affective Disorders, Vol. 173, pp. 90-96.

Ben-Zur, H. (2009), “Coping styles and affect”, International Journal of Stress Management, Vol. 16 No. 2, p. 87.

Bhat, R., Singh, V.K., Naik, N., Kamath, C.R., Mulimani, P. and Kulkarni, N. (2020), “COVID 2019 outbreak: the disappointment in indian teachers", Asian Journal of Psychiatry, Vol. 50, p. 102047.

Bhujade, V.M. (2017), "Depression, anxiety and academic stress among college students: a brief review", Indian Journal of Health and Wellbeing, Vol. 8 No. 7.

Brougham, R.R., Zail, C.M., Mendoza, C.M. and Miller, J.R. (2009), "Stress, sex differences, and coping strategies among college students", Current Psychology, Vol. 28 No. 2, pp. 85-97.

Burger, K. and Samuel, R. (2017), "The role of perceived stress and self-efficacy in young people's life satisfaction: a longitudinal study", Journal of Youth and Adolescence, Vol. 46 No. 1, pp. 78-90.

Busari, A.O. (2012), "Evaluating the relationship between gender, age, depression and academic performance among secondary school students", International Journal of Interdisciplinary and Multidisciplinary Studies, Vol. 4 No. 2, pp. 6-12.

Chao, R.C.L. (2012), "Managing perceived stress among college students: the roles of social support and dysfunctional coping", Journal of College Counseling, Vol. 15 No. 1, pp. 5-21.

Çivitci, A. (2015), "Perceived stress and life satisfaction in college students: belonging and extracurricular participation as moderators", Procedia-Social and Behavioral Sciences, Vol. 205, pp. 271-281. 
Coffman, D.L. and Gilligan, T.D. (2002), "Social support, stress, and self-efficacy: effects on students' satisfaction", Journal of College Student Retention: Research, Theory and Practice, Vol. 4 No. 1, pp. 53-66.

Cortina, J.M. (1993), "What is coefficient alpha? An examination of theory and applications", Journal of Applied Psychology, Vol. 78 No. 1, p. 98.

Insufficient efforts and academic stress

Craig, K., Hale, D., Grainger, C. and Stewart, M.E. (2020), "Evaluating metacognitive self-reports: systematic reviews of the value of self-report in metacognitive research", Metacogn. Learn, pp. 1-59, doi: 10.1007/s11409-020- 09222-y.

Danielsen, A.G., Samdal, O., Hetland, J. and Wold, B. (2009), "School-related social support and students' perceived life satisfaction”, The Journal of Educational Research, Vol. 102 No. 4, pp. 303-320, doi: 10.3200/JOER.102.4.303-320.

De Dreu, C.K., Van Dierendonck, D. and Dijkstra, M.T. (2004), "Conflict at work and individual wellbeing", International Journal of Conflict Management, Vol. 15 No. 1.

de la Fuente, J., Zapata, L., Martínez-Vicente, J.M., Sander, P. and Putwain, D. (2015), "Personal selfregulation, self-regulated learning and coping strategies, in university context with stress", in Pena-Ayala, A. and Cardenas, L. (Eds), Metacognition: Fundaments, Applications, and Trends, Vol. 76, Springer, London, pp. 39-72.

Deb, S., Strodl, E. and Sun, J. (2014), “Academic-related stress among private secondary school students in India”, Asian Education and Development Studies, Vol. 3 No. 2.

Diener, E. and Suh, E. (1997), "Measuring quality of life: economic, social, and subjective indicators", Social Indicators Research, Vol. 40, pp. 189-216.

Diener, E.D., Emmons, R.A., Larsen, R.J. and Griffin, S. (1985), “The satisfaction with life scale”, Journal of Personality Assessment, Vol. 49 No. 1, pp. 71-75.

Eid, M. and Diener, E. (2004), "Global judgments of subjective well-being: situational variability and long-term stability", Social Indicators Research, Vol. 65 No. 3, pp. 245-277.

Forehand, R., Wierson, M., Thomas, A.M., Armistead, L., Kempton, T. and Neighbors, B. (1991), "The role of family stressors and parent relationships on adolescent functioning", Journal of the American Academy of Child and Adolescent Psychiatry, Vol. 30 No. 2, pp. 316-322.

Fornell, C. and Larcker, D.F. (1981), "Evaluating structural equation models with unobservable variables and measurement error", Journal of Marketing Research, Vol. 18 No. 1, pp. 39-50.

Freire, C., Ferradás, M., Núñez, J., Valle, A. and Vallejo, G. (2018), “Eudaimonic well-being and coping with stress in university students: the mediating/moderating role of self-efficacy", International Journal of Environmental Research and Public Health, Vol. 16 No. 1, p. 48.

Fuller, J.A., Stanton, J.M., Fisher, G.G., Spitzmüller, C., Russell, S.S. and Smith, P.C. (2003), “A lengthy look at the daily grind: time series analysis of events, mood, stress, and satisfaction", Journal of Applied Psychology, Vol. 88 No. 6, pp. 1019-1033.

Garg, N. and Saxena, A. (2020), "Analyzing the inter-relation between workplace spirituality and constructive deviance”, Asian journal of Business Ethics, Vol. 9, pp. 121-141.

Gerasimova, N. and Gerasymova, I. (2019), "The influence of intrapersonal conflicts on the course of adaptation of students at the establishment of higher education", Sustainable Development under the Conditions of European Integration, Vol. Part I, p. 384.

Gross, J.J. (2014), Handbook of Emotion Regulation, 2nd ed, Guilford, New York, NY.

Gross, J.J. (2015a), "Emotion regulation: current status and future prospects", Psychological Inquiry, Vol. 26 No. 1, pp. 1-26.

Gross, J.J. (2015b), “The extended process model of emotion regulation: elaborations, applications, and future directions", Psychological Inquiry, Vol. 26 No. 1, pp. 130-137. 
RAMJ

15,2

Grubic, N., Badovinac, S. and Johri, A.M. (2020), "Student mental health in the midst of the COVID-19 pandemic: a call for further research and immediate solutions", International Journal of Social Psychiatry, p. 0020764020925108.

Gupta, K. and Khan, B.N. (1987), “Anxiety level as a factor in concept formation”, J. Psychol. Reports, Vol. 31, pp. 187-192.

Hair, J.F., Black, W.C., Babin, B.J., Anderson, R.E. and Tatham, R.L. (1998), Multivariate Data Analysis, Vol. 5, Prentice hall Upper Saddle River, NJ.

Hu, L. and Bentler, P.M. (1999), "Cutoff criteria for fit indexes in covariance structure analysis: conventional criteria versus new alternatives", Structural Equation Modeling: A Multidisciplinary Journal, Vol. 6 No. 1, pp. 1-55.

Huang, N., Qiu, S., Alizadeh, A. and Wu, H. (2020), "How incivility and academic stress influence psychological health among college students: the moderating role of gratitude", International Journal of Environmental Research and Public Health, Vol. 17 No. 9, p. 3237.

Jamadin, N., Mohamad, S., Syarkawi, Z. and Noordin, F. (2015), "Work-family conflict and stress: evidence from Malaysia", Journal of Economics, Business and Management, Vol. 3 No. 2, pp. 309-312.

Jaramillo, F., Mulki, J.P. and Boles, J.S. (2011), "Workplace stressors, job attitude, and job behaviors: is interpersonal conflict the missing link?", Journal of Personal Selling and Sales Management, Vol. 31 No. 3, pp. 339-356.

Jenkins, S.R., Belanger, A., Connally, M.L., Boals, A. and Durón, K.M. (2013), "Firstgeneration undergraduate students' social support, depression, and life satisfaction", Journal of College Counseling, Vol. 16 No. 2, pp. 129-142.

Kadapatti, M.G. and Vijayalaxmi, A.H.M. (2012), "Stressors of academic stress - a study on preuniversity students", Indian Journal of Scientific Research, Vol. 3 No. 1, pp. 171-175.

Karatepe, O.M. and Baddar, L. (2006), "An empirical study of the selected consequences of frontline employees' work-family conflict and family-work conflict", Tourism Management, Vol. 27 No. 5, pp. 1017-1028.

Keenan, A. and Newton, T.J. (1985), "Stressful events, stressors and psychological strains in young professional engineers", Journal of Organizational Behavior, Vol. 6 No. 2, pp. 151-156.

Kline, R.B. (2011), "Methodology in the social sciences", Principles and Practice of Structural Equation Modeling, (3rd ed.), Guilford Press.

Kohn, J.P. and Frazer, G.H. (1986), "An academic stress scale: identification and rated importance of academic stressors”, Psychological Reports, Vol. 59 No. 2, pp. 415-426.

Kong, F., Ding, K. and Zhao, J. (2015), "The relationships among gratitude, self-esteem, social support and life satisfaction among undergraduate students", Journal of Happiness Studies, Vol. 16 No. 2, pp. 477-489.

Kumaraswamy, N. (2013), "Academic stress, anxiety and depression among college students: a brief review”, International Review of Social Sciences and Humanities, Vol. 5 No. 1, pp. 135-143.

Lakaev, N. (2009), "Validation of an australian academic stress questionnaire", Australian Journal of Guidance and Counselling, Vol. 19 No. 1, pp. 56-70.

Lauterbach, W. (1991), "Intrapersonal conflict, life stress, and emotion”, Stress and Anxiety, Vol. 13, pp. 85-92.

Lee, M. and Larson, R. (2000), “The korean 'examination hell': long hours of studying, distress, and depression”, Journal of Youth and Adolescence, Vol. 29 No. 2, pp. 249-271.

Longobardi, C., Prino, L.E., Marengo, D. and Settanni, M. (2016), "Student-teacher relationships as a protective factor for school adjustment during the transition from middle to high school", Frontiers in Psychology, Vol. 7, p. 1988. 
Mikolaj, E.L. and Boggs, D.L. (1991), "Intrapersonal role conflicts of adult women undergraduate students", The Journal of Continuing Higher Education, Vol. 39 No. 2, pp. 13-19.

Miller, B. (1989), “Adult children's perceptions of caregiver stress and satisfaction”, Journal of Applied Gerontology, Vol. 8 No. 3, pp. 275-293.

Mishra, R. and Mckean, M. (2020), "College students' academic stress and its relation to their anxiety, time management, and leisure satisfaction", American Journal of Health Studies, Vol. 16 No. 1, pp. 41-51.

Nandamuri, P. and Gowthami, C. (2011), "Sources of academic stress - a study on management students", Journal of Management and Science, Vol. 1 No. 2, pp. 31-42.

Ne, M.W. and Cudeck, R. (1993), “Alternative ways of assessing model fit”, Testing Structural Equation Models, Vol. 154, p. 136.

Ng, J.C., Lau, V.C. and Chen, S.X. (2020), "Why are dispositional enviers not satisfied with their lives? An investigation of intrapersonal and interpersonal pathways among adolescents and young adults", Journal of Happiness Studies, Vol. 21 No. 2, pp. 525-545.

Norcross, J.C., Prochaska, J.O. and Hambrecht, M. (1985), "Levels of attribution and change (Lac) scale: development and measurement", Cognitive Therapy and Research, Vol. 9 No. 6, pp. 631-649.

Nunnally, J.C. (1994), Psychometric Theory 3E, Tata McGraw-Hill Education.

Phang, C.K., Mukhtar, F., Ibrahim, N., Keng, S.L. and Sidik, S.M. (2015), "Effects of a brief mindfulness-based intervention program for stress management among medical students: the mindful-gym randomized controlled study", Advances in Health Sciences Education, Vol. 20 No. 5, pp. 1115-1134.

Podsakoff, P.M., MacKenzie, S.B., Lee, J.Y. and Podsakoff, N.P. (2003), "Common method biases in behavioral research: a critical review of the literature and recommended remedies", Journal of Applied Psychology, Vol. 88 No. 5, pp. 879-903.

Pyhältö, K., Soini, T. and Pietarinen, J. (2010), "Pupils' pedagogical well-being in comprehensive school - significant positive and negative school experiences of finnish ninth graders", European Journal of Psychology of Education, Vol. 25 No. 2, pp. 207-221.

Saxena, A., Garg, N., Punia, B.K. and Prasad, A. (2020), "Exploring role of indian workplace spirituality in stress management: a study of oil and gas industry", Journal of Organizational Change Management, Vol. 33 No. 5.

Schat, A.C., Frone, M.R. and Kelloway, E.K. (2006), "Prevalence of workplace aggression in the US workforce: findings from a national study".

Sharma, B., Kumar, A. and Sarin, J. (2016), “Academic stress, anxiety, remedial measures adopted and its satisfaction among medical students: a systematic review", International Journal of Health Sciences and Research, Vol. 6, pp. 368-376.

Sheroun, D., Wankhar, D.D., Devrani, A., Lissamma, P.V., Gita, S. and Chatterjee, K. (2020), "A study to assess the perceived stress and coping strategies among B.Sc. nursing students of selected colleges in Pune during COVID-19 pandemic lockdown", International Journal of Science and Healthcare Research, Vol. 5 No. 2, pp. 280-288.

Sposito, V.A., Hand, M.L. and Skarpness, B. (1983), "On the efficiency of using the sample kurtosis in selecting optimal lpestimators", Communications in Statistics - Simulation and Computation, Vol. 12 No. 3, pp. 265-272.

Stevens, J.P. (2012), Applied Multivariate Statistics for the Social Sciences, Routledge.

Subramani, C. and Kadhiravan, S. (2017), "Academic stress and mental health among high school students”, Indian Journal of Applied Research, Vol. 7 No. 5, pp. 404-406.

Taniguchi, H. and Kato, T. (2018), "The frequencies and effects of interpersonal stress coping with different types of interpersonal stressors in friendships on mental health and subjective wellbeing among college students", The Japanese Journal of Personality, pp. 27-33. 
RAMJ

15,2

Uchil, H.B. (2017), "The effect of stress on students' performance”, Stress Management Professional International Journal, Vol. 5 No. 1, pp. 17-21.

Verma, G. and Verma, H. (2020), "Model for predicting academic stress among students of technical education in India”, International Journal of Psychosocial Rehabilitation, Vol. 24 No. 04, pp. 2702-2714.

Virtanen, T.E., Vaaland, G.S. and Ertesvåg, S.K. (2019), “Associations between observed patterns of classroom interactions and teacher wellbeing in lower secondary school”, Teaching and Teacher Education, Vol. 77, pp. 240-252.

Wang, D., Wang, X. and Xia, N. (2018), "How safety-related stress affects workers' safety behavior: the moderating role of psychological capital”, Safety Science, Vol. 103, pp. 247-259.

Wilks, S.E. (2008), "Resilience amid academic stress: the moderating impact of social support among social work students", Advances in Social Work, Vol. 9 No. 2, pp. 106-125.

Zeidner, M. (1992), "Sources of academic stress: the case of first year Jewish and Arab college students in Israel", Higher Education, Vol. 24 No. 1, pp. 25-40.

\section{Further reading}

Calaguas, G.M. (2012), "Survey of college academic stressors: development of a new measure”, Journal of Human Sciences, Vol. 9 No. 1, pp. 441-457.

\section{Corresponding author}

Naval Garg can be contacted at: naval.garg@dtu.ac.in

For instructions on how to order reprints of this article, please visit our website: 